\title{
Disclosure of Disability by University Students: Development of a Study Protocol
}

\author{
Andrea De Cesarei \\ Department of Psychology, University of Bologna, Bologna, Italy \\ Email: andrea.decesarei@unibo.it
}

Received 5 June 2014; revised 20 July 2014; accepted 5 August 2014

Copyright (C) 2014 by author and Scientific Research Publishing Inc.

This work is licensed under the Creative Commons Attribution International License (CC BY). http://creativecommons.org/licenses/by/4.0/

(c) (7) Open Access

\begin{abstract}
Within the life course of a person with disability, higher education represents an important step, and the disclosure of a disability is one of the first and most important choices that the person with disability has to take. Based on a review of the literature, it is described how a research protocol for investigating the effects of Self Efficacy and Metacognition on the Disclosure of Disability by university students is developed. These data would provide information concerning the predictive effects of the metacognitive skills, social support and self-efficacy on the attitudes towards the disclosure of a disability.
\end{abstract}

\section{Keywords}

Disability, Disclosure, Study Protocol

\section{Introduction}

In the most recent definition, disability is not intended as a condition that exclusively applies to a medically-impaired minority of people, but as a set of decrements in health that might concern every person, for instance throughout normal aging or during a disease [1]. This definition largely differs from the medical or biological model, and emphasizes the role that society barriers play [2]-[4]. Within the life course of a person with disability, higher education in university represents an important step. During the university career, people build their competences concerning personal, social and professional skills. The university years are an intermediate step between high school and adult work. Therefore, the student who just reached adulthood faces, potentially for the first time, a new environment which characteristics are different from high school and demands more in terms of personal, social and organizational skills. In a perspective that emphasizes the active participation of persons with disability, it is central to focus on the choices that the person takes, and on the internal and external motives that guide these choices. 
The disclosure of a disability is one of the first and most important choices that people with disability have to take. Declaring oneself as a person with disability exposes to positive consequences, such as the chance to receive support or accommodations throughout the university career. However, it is well documented that negative consequences, such as stigma, are also associated to disclosure of disability [5]-[7]. Several studies investigated the factors which are associated to the disclosure of disability. It has been reliably shown that external factors, for instance related to the sociodemographic status, contribute to the decision of disclosing oneself. The disclosure of a disability is defined as the moment in which the student communicates any disability status or limitation that requires support or accommodation to be successfully carried out [8] [9]. As such, disclosing a disability is a process which comprises relational as well as psychological factors, and which can be modulated (for instance, anticipated or delayed) by contextual and personal factors.

Which factors influence the choice of disclosing a disability? It must be noted at the outset that disclosure may be a choice or not, depending on the visibility of the disability. When the disability is not visible, the students may choose whether or not to disclose their disability to their peers and university staff. On the other hand, for those students whose disability is highly visible, disclosure may be a forced choice. Nonetheless, both students with visible and non visible disabilities may vary in the degree to which they actively take part in the academic life, or prefer a more detached role. The present study protocol aims at investigating the factors which promoted a more positive attitude towards disclosure in those students who disclosed their disability. More specifically, the present protocol aims at investigating the effects of social support, self-efficacy and metacognitive skills on the attitudes towards disclosing a disability. Below, a rationale is provided for each of these three factors.

Social support plays a crucial role in the development of a disability. In the social model of disability, the way in which society (in this case, the university environment) responds to the person's needs determines whether the person's needs will turn into a disability [2]. In this regard, the academic environment may represent a special case for people with disabilities. For instance, it has been noted that few medical students disclose their disability, possibly because of the negative attitudes from the wider student body [10] [11]. More generally, the number of students who disclose a disability is higher in the social sciences, and lower in the hard sciences [12]-[14]. While the reasons of this inequality are not known, it must be acknowledged that this uneven distribution has consequences in terms of the social environment that the students encounter, and in the expertise that the professors and the staff develop concerning knowing and supporting different disabilities and needs.

Self-efficacy has been suggested as the most impacting factor that influences disclosure, with low self-efficacy acting as a barrier [15] [16]. Self-efficacy is a widely-accepted construct in personality psychology, and it has been shown to subtend a wealth of behaviors [17]. Self-efficacy has been defined as the beliefs that the motivation, cognitive resources, and courses of action needed to meet given situational demands can be mobilized. Depending on the domain in which self-efficacy is assessed, one can distinguish between a task-specific or state-like construct [18] [19] and a generalized self-efficacy. Generalized self-efficacy is defined as "one's belief in one's overall competence to effect requisite performances across a wide variety of achievement situations" [20].

Finally, the metacognitive skills are related to the constructs of "self determination" and "self-awareness", which have been indicated as critical dimensions of the students who manage to conduct a successful academic life [21]-[24]. Good metacognitive skills may help people with disabilities both improving their academic performance, thus increasing their self-efficacy [25]; in addition, good metacognitive skills may help students with a disability to communicate their needs and expectations [26]. It is important to distinguish between metacognitive knowledge and skills. While the first refers to the declarative knowledge about how a process works, in general and for a particular person, the latter refers to how this knowledge may be used to monitor and supervise one's activity [27] [28].

\section{Choice of Instruments}

The present study protocol aims at investigating the effects of social support, self-efficacy and metacognitive skills on the attitudes towards disclosing a disability. Below, details about the instruments which will be used to measure each dimension are provided.

\subsection{Demographic Assessment and Sample Description}

Participants will be contacted through the local Services for Students with Disabilities and Specific Learning 
Disabilities. In higher education, highly different conditions such as autism, psychiatric disorders, learning disabilities, sensory deficits, motor deficits are commonly encountered. Therefore, the type, severity and duration of disability will be assessed, and data will be analyzed separately for different types of disability (e.g., motor vs. sensory vs. specific learning disability). Additionally, disabilities differ in visibility; for instance, motor disabilities are typically visible as they require visible aids, while cognitive impairments, such as learning disorders, may not be evident at first sight. As previous studies indicated differences between conditions which differ in visibility, the degree to which people perceive that their disability is visible to the academic people will be assessed.

\subsection{Generalized Self-Efficacy}

General Self-Efficacy (GSE) reflects people's perception of their ability to perform well in a variety of situations. GSE can be measured through a 10-item psychometric scale that is widely available in several languages [29]. This scale is designed to assess optimistic self-beliefs to cope with a variety of difficult demands in life and provides an overall score reflecting GSE.

\subsection{Social Support}

The perception of social support reflects the scanning of the resources which are provided by significant individuals or groups, in terms of the functional support that each can provide [30]. In terms of measures, the Interpersonal Support Evaluation List (ISEL) assesses the perceived availability of functional social support resources [30] [31]. The ISEL is a 40-item scale, which contains four subscales that measure appraisal of support, availability of tangible support, self-esteem items, and sense of belonging [31] [32].

\subsection{Metacognitive Skills}

Metacognition can be differentiated into knowledge and skills [33], with the first referring to the knowledge and understanding of one's own cognitive processes [27], and the latter to the voluntary control that people have over their own cognitive processes [34]. Metacognition can be assessed prospectively, retrospectively or concurrently to performances. In prospective methods, such as self-report questionnaires and hypothetical interview, students have to indicate whether a statement (e.g., "I have to mentally repeat the information I just read") well describes their behavior [35] [36]. In contrast, retrospective techniques aim at post-hoc reconstructing the cognitive processes that have taken place [37]. Finally, concurrent assessment can be carried out by asking people to verbalize their thoughts while they are carrying out a task. Here, concurrent assessment will be carried out as it allows one to monitor on-line the specific processes that students use and the thoughts they report about their performances. A text of intermediate length will be selected from an introductory textbook, and participants will be asked to study it and prepare themselves as if they had to summarize it as homework. During this task, participants will have to verbalize aloud their cognitive processes. The input of the interviewer will be set at a minimum level, on the one hand to avoid that the participants do not report anything (thus not complying with task demands), and on the other hand not to promote a deeper metacognitive processing. Data will be scored according to the criteria described in Meijer et al. [38], separately for planning, monitoring, and evaluation of performance.

\subsection{Attitudes towards Disclosing a Disability}

Based on previous qualitative research on the experiences of university students with disabilities, a questionnaire was recently developed which examines attitudes in four separate dimensions, namely academic integrity, disability disclosure, disability acceptance, and the accommodation process [39]-[42]. Not surprisingly given that the scale includes questions about disability disclosure, the questionnaire predicts differences in requesting accommodations [42]. More interestingly, it has been shown that similar scores are obtained when the questionnaire is filled online and in paper-and-pencil form, with the remarkable exception of students with visible disabilities, with more positive attitudes towards requesting accommodations are observed when the questionnaire is filled out online compared to in person [40]. High scores on these scales might signal the need for an intervention, for example by putting the student in contact with specialized tutors who can provide more information and facilitate the communication with the disability services staff. 


\section{Planned Analysis and Expected Results}

The data will be analyzed through a hierarchical multiple regression, with scores on the attitudes questionnaire as dependent variables. Separate regressions will be carried out for the global attitude score, and for each of the subscales (academic integrity, disability disclosure, disability acceptance, and the accommodation process). Predictors will be added in successive steps, proceeding in a feed forward direction. Demographic variables (gender, age, academic age, school, type of disability, visibility of the disability) will be entered first. Then, scores for each of the scale concerning social support, metacognitive skills and generalized self-efficacy will be entered as predictors.

It is expected that the present design will provide information concerning the factors that modulate attitudes towards disclosing a disability and requesting accommodations. More specifically, it is expected that the effects of self-efficacy will be highly significant, as this factor has been shown to modulate a wide range of behaviors [17]. Concerning social support and metacognitive skills, it is possible that the effects of these factors are exerted only indirectly through a mediation by self-efficacy. If this is the case, then any significant effect of social support and metacognitive skills should be canceled out once self-efficacy is controlled for in the regression analysis.

Finally, a smaller variability in attitudes towards disclosing a disability and requesting accommodations might be observed in people with a visible disability compared to people with a non visible disability, as exposing their disability may be a forced option for them [40]. However, it is expected that for both groups (visible and not visible disabilities) a significant effect of self-efficacy will be observed.

\section{Conclusions}

It is expected that these data will provide information about the conditions which facilitate communication and disclosure, in a group of declared students with disability. This information may be of interest for professionals working with students with disabilities in the higher education setting, to promote conditions that facilitate the communication between those students who have chosen to disclose that they have a disability, and the academic world.

Additionally, these data may suggest which factors deterred disclosure in those students who did not communicate their disability. Although no data are collected from this "invisible" group, it is likely that similar factors modulate the attitudes towards requesting help or accommodation for a disability. This information can be used in wide-range programs (e.g., during introductory or orientation meetings) to promote these facilitating conditions for all students who are experiencing a difficulty or a disability.

\section{References}

[1] World Health Organization (2001) International Classification of Functioning, Disability and Health (ICF). World Health Organization, Geneva.

[2] Finkelstein, V. (1980) Attitudes and Disabled People: Issues for Discussion. World Rehabilitation Fund, New York.

[3] Shakespeare, T. and Watson, N. (2001) The Social Model of Disability: An Outdated Ideology? In: Research in Social Science and Disability, Volume 2, Exploring Theories and Expanding Methodologies, Elsevier Science Ltd., Berlin, 9-28.

[4] Tomas, C. (2004) How Is Disability Understood? An Examination of Sociological Approaches. Disability \& Society, 19, 569-583. http://dx.doi.org/10.1080/0968759042000252506

[5] Caruso, D. and Hodapp, R.M. (1988) Perceptions of Mental Retardation and Mental Illness. American Journal on Mental Retardation, 93, 118-124.

[6] Hardman, M.L. and Clark, C. (2006) Promoting Friendship through Best Buddies: A National Survey of College Program Participants. Mental Retardation, 44, 56-63. http://dx.doi.org/10.1352/0047-6765(2006)44[56:PFTBBA]2.0.CO;2

[7] Martin, J.M. (2010) Stigma and Student Mental Health in Higher Education. Higher Education Research and Development, 29, 259-274. http://dx.doi.org/10.1080/07294360903470969

[8] Greene, K., Derlega, V. J. and Mathews, A. (2006) Self-Disclosure in Personal Relationships. In: Vangelisti, A. and Perlman, D., Eds., Cambridge Handbook of Personal Relationships, Cambridge University Press, Cambridge, 409-427. http://dx.doi.org/10.1017/CBO9780511606632.023 
[9] Rocco, T.S. (2004) Towards a Model of Disability Disclosure. Midwest Research-to-Practice Conference in Adult, Continuing, and Community Education, Indiana University, Indianapolis.

[10] Miller, S.C., Ross, S. and Cleland, J.A. (2009) Courses Arranged to Suit my Needs: Medical Student Attitudes towards Disability and Support for Disability in Medicine. Medical Teacher, 31, 556-561. http://dx.doi.org/10.1080/01421590802516814

[11] Morris, D.K. and Turnbull, P. (2007) The Disclosure of Dyslexia in Clinical Practice: Experiences of Student Nurses in the United Kingdom. Nurse Education Today, 27, 35-42. http://dx.doi.org/10.1016/j.nedt.2006.01.017

[12] Eden, S. and Heiman, T. (2011) Computer Mediated Communication: Social Support for Students with and without Learning Disabilities. Educational Technology \& Society, 14, 89-97.

[13] Heiman, T. (2006) Social Support Networks, Stress, Sense of Coherence and Academic Success of University Students with Learning Disabilities. Social Psychology of Education, 9, 461-478. http://dx.doi.org/10.1007/s11218-006-9007-6

[14] Nevill, R.E.A. and White, S.W. (2011) College Students’ Openness toward Autism Spectrum Disorders: Improving Peer Acceptance. Journal of Autism and Developmental Disorders, 41, 1619-1628. http://dx.doi.org/10.1007/s10803-011-1189-X

[15] Getzel, E.E. and Thoma, C.A. (2008) Experiences of College Students with Disabilities and the Importance of Self-Determination in Higher Education Settings. Career Development and Transition for Exceptional Individuals, 31, 77-84. http://dx.doi.org/10.1177/0885728808317658

[16] Hartman-Hall, H.M. and Haaga, D.A.F. (2002) College Students’ Willingness to Seek Help for Their Learning Disabilities. Learning Disability Quarterly, 25, 263-274. http://dx.doi.org/10.2307/1511357

[17] Bandura, A. (1977) Social Learning Theory. Prentice Hall, Englewood Cliffs.

[18] Gist, M.E. and Mitchell, T.R. (1992) Self-Efficacy: A Theoretical Analysis of Its Determinants and Malleability. Academy of Management Review, 17, 183-211. http://dx.doi.org/10.5465/AMR.1992.4279530

[19] Lee, C. and Bobko, P. (1994) Self-Efficacy Beliefs: Comparison of Five Measures. Journal of Applied Psychology, 79, 364-369. http://dx.doi.org/10.1037/0021-9010.79.3.364

[20] Eden, D. (2001) Means Efficacy: External Sources of General and Specific Efficacy. In: Erez, M. and Kleinbeck, U., Eds., Work Motivation in the Context of a Globalizing Economy, Lawrence Erlbaum, Mahwah, 73-85.

[21] Belch, H.A. (2005) Retention and Students with Disabilities. Journal of College Student Retention, 6, 3-22. http://dx.doi.org/10.2190/MC5A-DHRV-1GHM-N0CD

[22] Jameson, D.R. (2007) Self-Determination and Success Out-Comes of Two-Year College Students with Disabilities. Journal of College Reading and Learning, 37, 26-46. http://dx.doi.org/10.1080/10790195.2007.10850196

[23] Wehmeyer, M.L. and Palmer, S.B. (2003) Adult Outcomes for Students with Cognitive Disabilities Three Years after High School: The Impact of Self-Determination. Education and Training in Developmental Disabilities, 38, 131-144.

[24] Marshak, L., Van Wieren, T. and Ferrell, D. (2010) Exploring Barriers to College Student Use of Disability Services and Accommodations. Journal of Postsecondary Education and Disability, 22, 151-165.

[25] Pintrich, P.R. and De Groot, E.V. (1990) Motivational and Self-Regulated Learning Components of Classroom Academic Performance. Journal of Educational Psychology, 82, 33-40. http://dx.doi.org/10.1037/0022-0663.82.1.33

[26] Pintrich, P.R., Anderman, E.M. and Klobucar, C. (1992) Intraindividual Differences in Motivation and Cognition in Students with and without Learning Disabilities. Journal of Learning Disabilities, 27, 360-370. http://dx.doi.org/10.1177/002221949402700603

[27] Flavell, J.H. (1971) First Discussant's Comments: What Is Memory Development the Development of? Human Development, 14, 272-278. http://dx.doi.org/10.1159/000271221

[28] Veenman, M.V.J., Hout-Wolters, B.H.M. and Afflerbach, P. (2006) Metacognition and Learning: Conceptual and Methodological Considerations. Metacognition and Learning, 1, 3-14. http://dx.doi.org/10.1007/s11409-006-6893-0

[29] Schwarzer, R. and Jerusalem, M. (1995) Generalized Self-Efficacy Scale. In: Weinman, J., Wright, S. and Johnston, M., Eds., Measures in Health Psychology: A User's Portfolio, Causal and Control Beliefs, NFER-NELSON, Windsor, 35-37.

[30] Cohen S., Mermelstein R., Kamarck T. and Hoberman, H.M. (1985) Measuring the Functional Components of Social Support. In: Sarason, I.G. and Sarason, B.R., Eds., Social Support: Theory, Research and Applications, Martinus Niijhoff, 73-94.

[31] Cohen, S. and Hoberman, H. (1983) Positive Events and Social Supports as Buffers of Life Change Stress. Journal of Applied Social Psychology, 13, 99-125. http://dx.doi.org/10.1111/j.1559-1816.1983.tb02325.x

[32] Brookings, J.B. and Bolton, B. (1988) Confirmatory Factor Analysis of the Interpersonal Support Evaluation List. American Journal of Community Psychology, 16, 137-147. http://dx.doi.org/10.1007/BF00906076 
[33] Lucangeli, D., Galderisi, D. and Cornoldi, C. (1995) Specific and General Transfer Effects Following Metamemory Training. Learning Disabilities Research \& Practice, 10, 11-21.

[34] Brown, A. (1987) Metacognition, Executive Control, Self-Regulation and Other More Mysterious Mechanisms. In: Weinert, F.E. and Kluwe, R.H., Eds., Metacognition, Motivation and Understanding, Hillsdale, 65-116.

[35] Elshout-Mohr, M., Meijer, J., van Daalen-Kapteijns, M. and Meeus, W. (2003) A Self-Report Inventory for Metacognition Related to Academic Tasks. 10th Conference of the European Association for Research on Learning and Instruction (EARLI), Padova, 26-30 August 2003.

[36] Vermunt, J.D.H.M. (1996) Metacognitive, Cognitive and Affective Aspects of Learning Styles and Strategies: A Phenomenographic Analysis. Higher Education, 31, 25-50. http://dx.doi.org/10.1007/BF00129106

[37] Artelt, C. (2000) Wie Prädiktiv sind Retrospektive Selbstberichte über den Gebrauch von Lernstrategien für Strategisches Lernen? German Journal of Educational Psychology, 14, 72-84.

[38] Meijer, J., Veenman, M.V.J. and van Hout-Wolters, B.H.A.M. (2006) Metacognitive Activities in Text-Studying and Problem-Solving: Development of a Taxonomy. Educational Research and Evaluation, 12, 209-237. http://dx.doi.org/10.1080/13803610500479991

[39] Barnard, L. and Lan, W.Y. (2007) Faculty Attitudes towards Persons with Disabilities When Controlling for Diversity Attitudes. International Journal of Diversity in Organisations, Communications and Nations, 7, 1-9.

[40] Barnard-Brak, L. and Sulak, T. (2010) Online versus Face-to-Face Accommodations among College Students with Disabilities. American Journal of Distance, 24, 81-91. http://dx.doi.org/10.1080/08923641003604251

[41] Barnard-Brak, L., Sulak, T., Tate, A. and Lechtenberger, D. (2010) Measuring College Students’ Attitudes toward Requesting Accommodations: A National Multi-Institutional Study. Assessment of Effective Intervention, 35, 141-147. http://dx.doi.org/10.1177/1534508409358900

[42] Barnard-Brak, L., Davis, T., Tate, A. and Sulak, T. (2009) Attitudes as a Predictor of College Students Requesting Accommodations. Journal of Vocational Rehabilitation, 31, 189-198. 
Scientific Research Publishing (SCIRP) is one of the largest Open Access journal publishers. It is currently publishing more than 200 open access, online, peer-reviewed journals covering a wide range of academic disciplines. SCIRP serves the worldwide academic communities and contributes to the progress and application of science with its publication.

Other selected journals from SCIRP are listed as below. Submit your manuscript to us via either submit@scirp.org or Online Submission Portal.
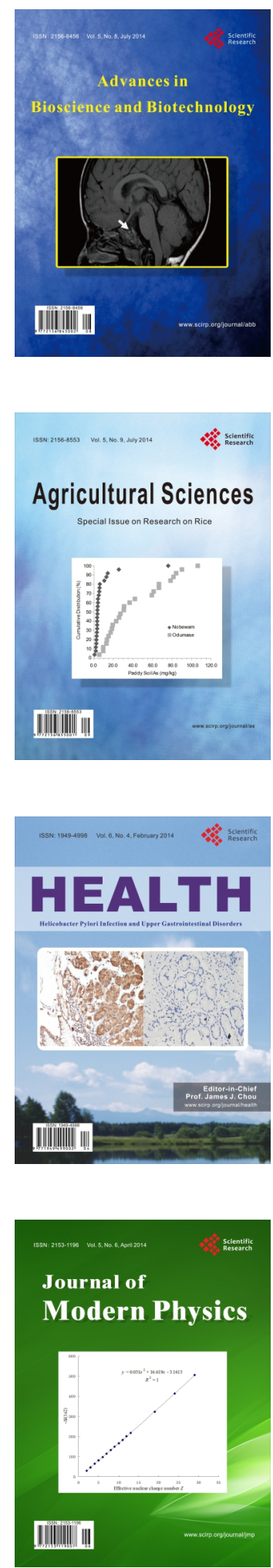
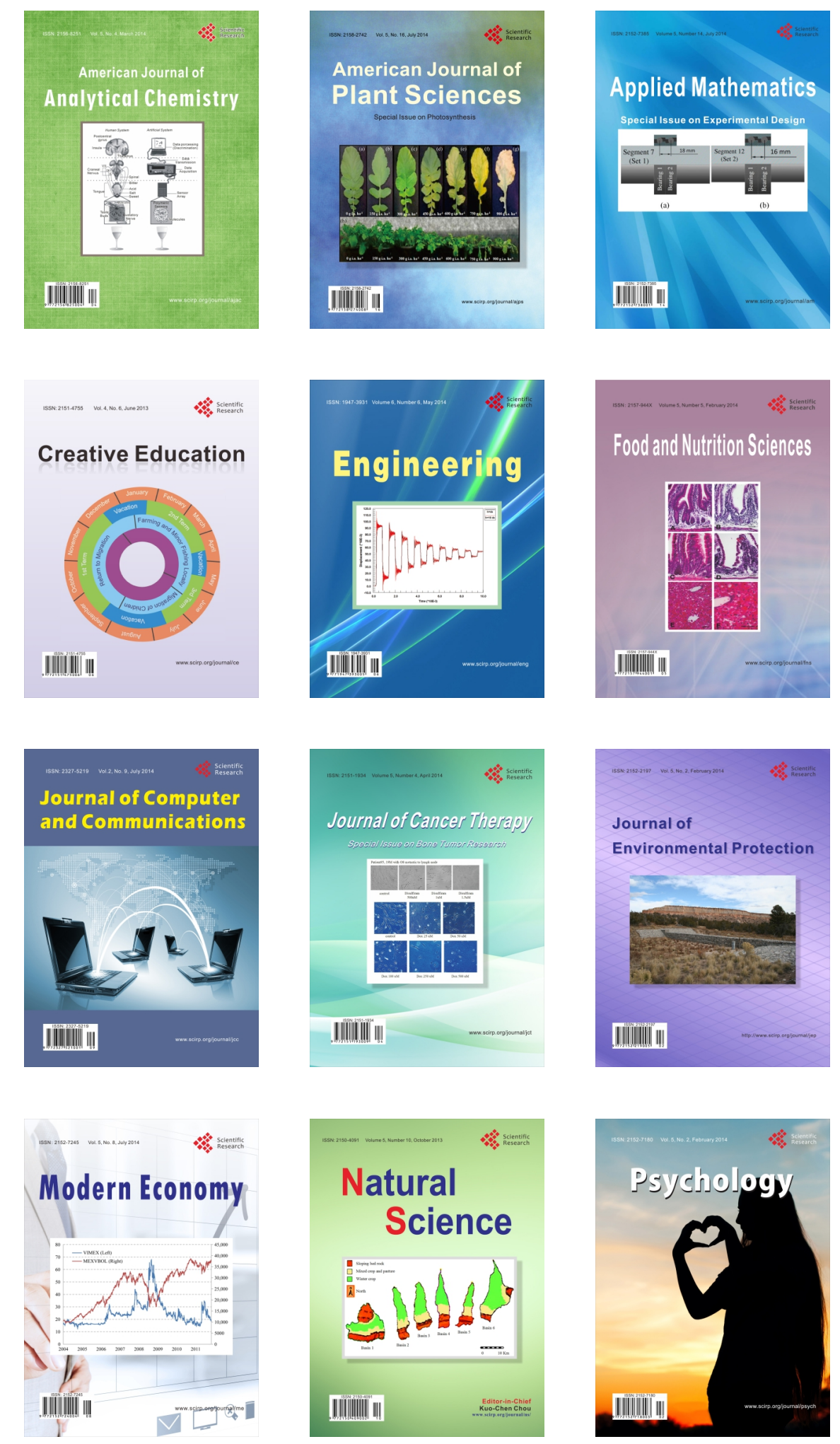